\title{
Lactobacillus saerimneri sp. nov., isolated from pig faeces
}

Correspondence

Stefan Roos

stefan.roos@mikrob.slu.se

\author{
Carsten Pedersen ${ }^{1}$ and Stefan Roos ${ }^{2}$
}

\author{
'Department of Animal Nutrition and Management, Swedish University of Agricultural Sciences, \\ Box 7024, SE-750 07 Uppsala, Sweden \\ ${ }^{2}$ Department of Microbiology, Swedish University of Agricultural Sciences, Box 7025, \\ SE-750 07 Uppsala, Sweden
}

The seven strains GDA154 ${ }^{\mathrm{T}}$, GDA158, GDA159, GDA160, GDA164, GDA166 and GDA170 were isolated from pig faeces in a study to determine the effect of different diets on the diversity of lactobacilli (C. Pedersen and others, unpublished results). The first four strains originated from one animal and the latter three from a second animal. Strains GDA154 $4^{\mathrm{T}}$ and GDA164 have been deposited in the Belgian Co-ordinated Collections of Microorganisms (BCCM, Gent, Belgium), the Deutsche Sammlung von Mikroorganismen und Zellkulturen (DSMZ, Braunschweig, Germany) and the Culture Collection, University of Göteborg (CCUG, Gothenburg, Sweden). Primary isolation was on Rogosa agar (Merck) in anaerobic jars under a $\mathrm{CO}_{2}+\mathrm{N}_{2}$ atmosphere (GasPak Plus system; BBL) at $37^{\circ} \mathrm{C}$. All further cultivation was performed at $37^{\circ} \mathrm{C}$ in anaerobic jars on MRS agar (Oxoid) or in MRS broth (Oxoid) unless otherwise stated.

Bacterial DNA was isolated using the DNeasy Tissue kit (Qiagen). The almost complete 16S rRNA gene for the strains was amplified using PCR with domain Bacteriaspecific primers (Weizenegger et al., 1992). The resulting PCR products were purified using the Qiagen PCR Purification kit. The first part (approximately $500 \mathrm{bp}$ ) of the purified fragments was sequenced according to standard methods. For strain GDA $154^{\mathrm{T}}$, the whole fragment was sequenced. Primers that were used for amplification, together with additional internal primers, were also used for sequencing of the PCR products. The sequences determined from the novel isolates were used for searches

Published online ahead of print on 27 February 2004 as DOI 10.1099/ ijs.0.3057-0.

Abbreviation: $m$-DAP, meso-diaminopimelic acid.

The GenBank/EMBL/DDBJ accession number for the 16S rRNA gene sequence of Lactobacillus saerimneri GDA $154^{\top}$ is AY 255802. in the GenBank database (http://www.ncbi.nlm.nih.gov/). Sequences representing the closest matches were retrieved and then aligned using the CLUSTAL $\mathrm{W}$ program (Thompson et al., 1994). For all sequences, approximately $1450 \mathrm{nt}$ were used. A distance matrix was calculated using the DNADIST program of the PHYLIP package (Felsenstein, 1993) with the F84 parameter model, and a phylogenetic tree was constructed with the NEIGHBOR program. Statistical significance of the grouping was estimated by bootstrapping (100 replicates) using the programs SEQBOOT, DNADIST, NEIGHBOR and CONSENSE, all of which are from the PHYLIP package. The phylogenetic tree was displayed using the TREEVIEW program (Page, 1996).

Cell morphologies of the bacteria were observed by phasecontrast microscopy. Determination of Gram reactions was performed using the $\mathrm{KOH}$ method of Gregersen (1978). Sugar fermentation patterns and aesculin were determined using the API 50 CHL system (bioMérieux) in duplicate at $37^{\circ} \mathrm{C}$. Lactic acid configuration was determined using a test kit from Boehringer Mannheim. Catalase activity was determined by transferring fresh colonies from MRS agar to a glass slide and adding $5 \% \mathrm{H}_{2} \mathrm{O}_{2}$. Production of gas from glucose was assayed by growing the bacteria in MRS tubes containing Durham tubes. Electrophoretic analysis of whole-cell proteins was performed by the BCCM. Preparation of whole-cell protein extracts and SDS-PAGE analysis were performed as described by Pot et al. (1994). Normalized and digitized patterns were numerically analysed and clustered with the reference profiles in the SDSPAGE protein database at the BCCM Bacteria Collection. Cell-wall analysis was performed at the DSMZ. Preparation of cell walls and determination of peptidoglycan structure were carried out using the methods described by Schleifer (1985) and Schleifer \& Kandler (1972) with the modification that TLC on cellulose sheets was used instead of paper 




Leu. mesenteroides

Fig. 1. Unrooted phylogenetic tree derived from 16S rRNA gene sequence analysis showing the relationship of Lactobacillus saerimneri sp. nov. to all members of the Lactobacillus mali subgroup and some other representatives of the Lactobacillus caseiPediococcus group of lactobacilli. The sequence of Leuconostoc (Leu.) mesenteroides was used as an outgroup representative. Approximately $1450 \mathrm{nt}$ from each sequence were used for the alignment. Bar, $1 \%$ estimated sequence divergence. Numbers indicate bootstrap values for branch points. P., Pediococcus.

chromatography. The $\mathrm{G}+\mathrm{C}$ content of the DNA was determined at the DSMZ. DNA was isolated by chromatography on hydroxyapatite by the procedure of Cashion et al. (1977) and the G+C content was determined by HPLC as described by Mesbah et al. (1989).

The partial 16S rRNA sequences (i.e. the first $500 \mathrm{bp}$ ) from all strains showed $100 \%$ identity. The complete $16 \mathrm{~S}$ rRNA sequence of GDA $154^{\mathrm{T}}$ was analysed with the SIMILARITY MATRIX tool at Ribosomal Database Project II (http:// rdp.cme.msu.edu/html); the highest similarity values were found to Lactobacillus salivarius, Lactobacillus aviarius and Lactobacillus mali, with $95 \cdot 0,94 \cdot 8$ and $94 \cdot 6 \%$ similarity, respectively. The sequence was then aligned with the sequences of all members of the L. mali subgroup and some other representatives of the Lactobacillus caseiPediococcus group of lactobacilli, and this alignment was then used to construct a phylogenetic tree. This clearly placed the bacterium in the L. mali subgroup and confirmed the relationship to $L$. salivarius and L. aviarius (Fig. 1 ). The mean $\mathrm{G}+\mathrm{C}$ content of the DNA of strain GDA $154^{\mathrm{T}}$ was $42.9 \mathrm{~mol} \%$ and the peptidoglycan type was A1 $\gamma$ mesodiaminopimelic acid ( $m$-DAP)-direct. The considerable difference in $16 \mathrm{~S}$ rRNA gene sequence compared to all recognized lactobacilli shows that the isolated strains represent a novel species. This is confirmed by comparing the $\mathrm{G}+\mathrm{C}$ content and peptidoglycan type with other members of the L. mali subgroup (Table 1). The strains

Table 1. Differential characteristics of species in the Lactobacillus mali subgroup of lactobacilli

Species: 1, L. saerimneri sp. nov.; 2, L. algidus (data from Kato et al., 2000); 3, L. nagelii (Edwards et al., 2000); 4, L. mali (Kato et al., 2000; Hammes et al., 1992); 5, L. salivarius (Kandler \& Weiss, 1986); 6, L. aviarius (Hammes et al., 1992); 7, L. acidipiscis (Tanasupawat et al., 2000); 8, L. cypricasei (Lawson et al., 2001); 9, L. ruminus (Kandler \& Weiss, 1986); 10, L. agilis (Kandler \& Weiss, 1986); 11, L. equi (Morotomi et al., 2002); 12, L. animalis (Kandler \& Weiss, 1986); 13, L. murinus (Kandler \& Weiss, 1986). +, $\geqslant 90 \%$ strains positive; ,$- \geqslant 90 \%$ strains negative; $d, 11-89 \%$ strains positive; $W$, weakly positive; NA, no data available.

\begin{tabular}{|c|c|c|c|c|c|c|c|c|c|c|c|c|c|}
\hline Characteristic & 1 & 2 & 3 & 4 & 5 & 6 & 7 & 8 & 9 & 10 & 11 & 12 & 13 \\
\hline \multicolumn{14}{|l|}{ Acid from: } \\
\hline L-Arabinose & - & + & - & + & - & NA & - & $\mathrm{d}$ & - & - & - & $\mathrm{d}$ & + \\
\hline Ribose & - & + & - & NA & - & NA & + & - & - & + & $\mathrm{d}$ & - & + \\
\hline Galactose & - & + & + & + & + & d & + & + & + & + & + & + & + \\
\hline Salicin & - & + & + & + & $\mathrm{d}$ & + & $\mathrm{W}$ & + & + & + & $\mathrm{d}$ & + & $\mathrm{d}$ \\
\hline Cellobiose & - & d & + & d & - & + & - & + & + & + & - & + & + \\
\hline Melibiose & - & $\mathrm{d}$ & - & - & + & d & - & - & + & + & + & + & + \\
\hline Sucrose & + & - & - & + & + & + & - & - & + & + & - & + & + \\
\hline Trehalose & + & + & + & + & + & + & d & $\mathrm{d}$ & - & + & - & - & $\mathrm{d}$ \\
\hline D-Raffinose & - & - & - & - & + & + & - & - & + & + & - & - & + \\
\hline Hydrolysis of aesculin & - & + & + & NA & $\mathrm{d}$ & NA & + & + & + & + & + & + & + \\
\hline Growth at $45^{\circ} \mathrm{C}$ & + & - & + & NA & + & NA & - & - & d & + & + & + & + \\
\hline Lactic acid configuration & DL & $\mathrm{L}$ & DL & $\mathrm{L}$ & $\mathrm{L}$ & DL & $\mathrm{L}$ & NA & $\mathrm{L}$ & $\mathrm{L}$ & DL & $\mathrm{L}$ & $\mathrm{L}$ \\
\hline $\mathrm{G}+\mathrm{C}$ content $(\mathrm{mol} \%)$ & $42 \cdot 9$ & $36-37$ & NA & $32-34$ & $34-36$ & $39-43$ & $39-42$ & NA & $44-47$ & $43-44$ & $38-40$ & $41-44$ & $43-44$ \\
\hline Peptidoglycan type & $m$-DAP & $m$-DAP & NA & $m$-DAP & Lys-D-Asp & Lys-D-Asp & Lys-D-Asp & NA & $m$-DAP & $m$-DAP & NA & Lys-D-Asp & Lys-D-Asp \\
\hline
\end{tabular}




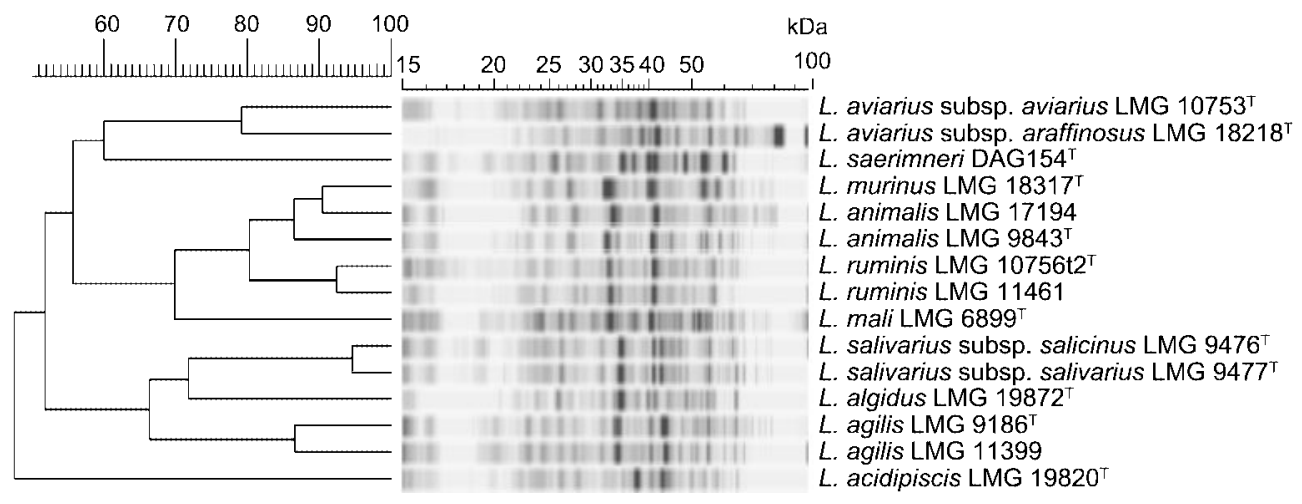

Fig. 2. Dendrogram derived from SDS-PAGE protein pattern analysis of Lactobacillus saerimneri sp. nov. and representative strains within the Lactobacillus mali subgroup of lactobacilli.

represent a novel species, for which we propose the name Lactobacillus saerimneri sp. nov., with strain $\mathrm{GDA}_{154^{\mathrm{T}}}$ as the type strain.

Strains GDA154 ${ }^{\mathrm{T}}$, GDA158 and GDA164 showed identical physiological properties; these are listed under the species description. These physiological properties clearly distinguish L. saerimneri from closely related species. Differential characteristics for members of the L. mali subgroup of lactobacilli are summarized in Table 1. Furthermore, electrophoretic analysis of whole-cell proteins showed that strain $\mathrm{GDA} 154^{\mathrm{T}}$ is distinct from other species in the L. mali subgroup of lactobacilli (Fig. 2).

The gastrointestinal microbiota of pigs has been analysed using 16S rRNA gene sequencing by Pryde et al. (1999) and Leser et al. (2002). Although many lactobacilli were detected, none has a $16 \mathrm{~S}$ rRNA gene sequence similar to L. saerimneri. This indicates that the bacterium is a minor component in the gastrointestinal microbiota of pigs.

\section{Description of Lactobacillus saerimneri sp. nov.}

Lactobacillus saerimneri (sae.rim'ne.ri. N.L. gen. masc. n. saerimneri of Saerimner, a pig occurring in Nordic mythology, because the organism was isolated from pigs).

Gram-positive, non-motile, non-spore-forming, catalasenegative rods, $1 \times 1 \cdot 5-4 \mu \mathrm{m}$ in size and occurring as single cells or in pairs. After anaerobic growth at $37^{\circ} \mathrm{C}$ for $48 \mathrm{~h}$, colonies on MRS agar are $2-3 \mathrm{~mm}$ in diameter; they are white with an opaque border, smooth and convex. Growth on MRS agar also occurs under aerobic conditions, but at a considerably lower rate. In MRS broth growth occurs between 15 (weak) and $45^{\circ} \mathrm{C}$. Both D- $(75 \%)$ and L-lactate $(25 \%)$ are produced. Gas is not produced from glucose. Acid is produced from D-glucose, D-fructose, D-mannose, $\mathrm{N}$-acetylglucosamine (delayed reaction), sucrose, trehalose and D-turanose. Acid is not produced from glycerol, erythritol, D-arabinose, L-arabinose, ribose, D-xylose, L-xylose, adonitol, methyl $\beta$-D-xyloside, galactose, L-sorbose, rhamnose, dulcitol, inositol, mannitol, sorbitol, methyl $\alpha$-D-mannoside, methyl $\alpha$-D-glucoside, amygdalin, arbutin, salicin, cellobiose, maltose, melibiose, lactose, inulin, melezitose, D-raffinose, starch, glycogen, xylitol, $\beta$-gentiobiose, D-lyxose, D-tagatose, D-fucose, L-fucose, D-arabitol, Larabitol, gluconate, 2-ketogluconate or 5-ketogluconate. Aesculin is not hydrolysed. The DNA G $+\mathrm{C}$ content of strain GDA $154^{\mathrm{T}}$ is $42.9 \mathrm{~mol} \%$ and the peptidoglycan type is A1 $\gamma$ m-DAP-direct. Phylogenetic analysis of the $16 \mathrm{~S}$ rRNA gene sequence places the species in the $L$. mali subgroup of lactobacilli.

The type strain is $\mathrm{GDA} 154^{\mathrm{T}}\left(=\mathrm{LMG} 22087^{\mathrm{T}}=\mathrm{DSM}\right.$ $16049^{\mathrm{T}}=$ CCUG $48462^{\mathrm{T}}$ ).

\section{Acknowledgements}

We thank Professor Dr H. G. Trüper for advice regarding nomenclature; BCCM, Gent, Belgium, for analysis of the protein profile and construction of the dendrogram; and DSMZ, Braunschweig, Germany, for analysis of DNA base composition and peptidoglycan type. We also wish to thank the Agricultural Society of Kristianstad, SBI Trading $A B$, Sweden, and Carl Tryggers Foundation for financial support.

\section{References}

Cashion, P., Holder-Franklin, M. A., McCully, J. \& Franklin, M. (1977). A rapid method for the base ratio determination of bacterial DNA. Anal Biochem 81, 461-466.

Edwards, C. G., Collins, M. D., Lawson, P. A. \& Rodriquez, A. V. (2000). Lactobacillus nagelii sp. nov., an organism isolated from a partially fermented wine. Int J Syst Evol Microbiol 50, 699-702.

Felsenstein, J. (1993). PHYLIP (Phylogeny Inference Package), version $3.5 \mathrm{c}$. Distributed by the author. Department of Genetics, University of Washington, Seattle, USA.

Gregersen, T. (1978). A rapid method for distinction of Gramnegative from Gram-positive bacteria. Eur J Appl Microbiol Biotechnol 5, 123-127.

Hammes, W. P., Weiss, N. \& Holzapfel, W. (1992). The genera Lactobacillus and Carnobacterium. In The Prokaryotes, 2nd edn, pp. 1535-1594. Edited by A. Balows, H. G. Trüper, M. Dworkin, W. Harder \& K.-H. Schleifer. New York: Springer. 
Kandler, O. \& Weiss, N. (1986). Genus Lactobacillus Beijerinck 1901, 212 ${ }^{\mathrm{AL}}$. In Bergey's Manual of Systematic Bacteriology, vol. 2, pp. 1209-1234. Edited by P. H. A. Sneath, N. S. Mair, M. E. Sharpe \& J. G. Holt. Baltimore: Williams \& Wilkins.

Kato, Y., Sakala, R. M., Hayashidani, H., Kiuchi, A., Kaneuchi, C. \& Ogawa, M. (2000). Lactobacillus algidus sp. nov., a psychrophilic lactic acid bacterium isolated from vacuum-packaged refrigerated beef. Int J Syst Evol Microbiol 50, 1143-1149.

Lawson, P. A., Papademas, P., Wacher, C., Falsen, E., Robison, R. \& Collins, M. D. (2001). Lactobacillus cypricasei sp. nov., isolated from Halloumi cheese. Int J Syst Evol Microbiol 51, 45-49.

Leser, T. D., Amenuvor, J. Z., Jensen, T. K., Lindecrona, R. H., Boye, M. \& Møller, K. (2002). Culture-independent analysis of gut bacteria: the pig gastrointestinal tract microbiota revisited. Appl Environ Microbiol 68, 673-690.

Mesbah, M., Premachandran, U. \& Whitman, W. B. (1989). Precise measurement of the $\mathrm{G}+\mathrm{C}$ content of deoxyribonucleic acid by high-performance liquid chromatography. Int J Syst Bacteriol 39, 159-167.

Morotomi, M., Yuki, N., Kado, Y., Kushiro, A., Shimazaki, T., Watanabe, K. \& Yuyama, T. (2002). Lactobacillus equi sp. nov., a predominant intestinal Lactobacillus species of the horse isolated from faeces of healthy horses. Int J Syst Evol Microbiol 52, 211-214.

Page, R. D. M. (1996). TREEVIEW: an application to display phylogenetic trees on personal computers. Comput Appl Biosci 12, 357-358.
Pot, B., Vandamme, P. \& Kersters, K. (1994). Analysis of electrophoretic whole-organism protein fingerprints. In Chemical Methods in Prokaryotic Systematics, pp. 493-521. Edited by M. Goodfellow \& A. G. O’Donnell. Chichester: Wiley.

Pryde, S. E., Richardson, A. J., Stewart, C. S. \& Flint, H. J. (1999). Molecular analysis of the microbial diversity present in the colonic wall, colonic lumen, and cecal lumen of a pig. Appl Environ Microbiol 65, 5372-5377.

Schleifer, K. H. (1985). Analysis of the chemical composition and primary structure of murein. Methods Microbiol 18, 123-156.

Schleifer, K. H. \& Kandler, O. (1972). Peptidoglycan types of bacterial cell walls and their taxonomic implications. Bacteriol Rev 36, 407-477.

Tanasupawat, S., Shida, O., Okada, S. \& Komagata, K. (2000). Lactobacillus acidipiscis sp. nov. and Weissella thailandensis sp. nov., isolated from fermented fish in Thailand. Int J Syst Evol Microbiol 50, 1479-1485.

Thompson, J. D., Higgins, D. G. \& Gibson, T. J. (1994). CLUSTAL W: improving the sensitivity of progressive multiple sequence alignment through sequence weighting, position-specific gap penalties and weight matrix choice. Nucleic Acids Res 22, 4673-4680.

Weizenegger, M., Neumann, M., Stackebrandt, E., Weiss, N. \& Ludwig, W. (1992). Eubacterium alactolyticum phylogenetically groups with Eubacterium limosum, Acetobactericum woodii and Clostridium barkeri. Syst Appl Microbiol 15, 32-36. 